\title{
Pengaruh Model Pembelajaran Contextual Teaching And Learning Berbantuan Alat Peraga Terhadap Hasil Belajar Siswa Pada Materi Sistem Pencernaan Manusia di Kelas VIII SMP Negeri 4 Melonguane
}

\author{
Beryd Magenda ${ }^{*}$, Ferny Tumbel ${ }^{2}$ \\ 1Jurusan Pendidikan IPA, FMIPA, Universitas Negeri Manado \\ ${ }^{2}$ Jurusan Pendidikan Biologi, FMIPA, Universitas Negeri Manado \\ "e-mail: lorismagenda@gmail.com
}

\begin{abstract}
Abstrak. Penelitian ini dilakukan untuk mengetahui pengaruh penggunaan model pembelajaran Contextual Teaching and Learning (CTL) berbantuan alat peraga terhadap hasil belajar siswa pada materi sistem pencernaan manusia. Penelitian ini dilaksanakan di SMP Negeri 4 Melonguane pada semester ganjil tahun ajaran 2019. 2020. Penelitian ini menggunakan metode eksperimen. Populasi dalam penelitian ini adalah seluruh siswa kelas VIII yang terdiri dari 2 kelas. Pengambilan sampel dilakukan pada 2 kelas yang tersedia, dengan jumlah masing-masing 19 siswa. Kelas VIII-A sebagai kelas eksperimen dan kelas VIII-B sebagai kelas kontrol. Data hasil belajar siswa diperoleh dari pretest dan posttest. Hasil penelitian menunjukkan bahwa pada uji perbedaan dua rerata (uji-t) pada taraf nyata 0,05 diperoleh thitung $=3,55$ dan $t_{\text {tabel }}=2,10$ sehingga menunjukkan bahwa rata-rata hasil belajar siswa yang menggunakan model pembelajaran CTL lebih tinggi dibandingkan rata-rata hasil belajar siswa yang menggunakan model konvensional. Sehingga, dapat disimpulkan bahwa terdapat pengaruh model pembelajaran CTL berbantuan alat peraga terhadap hasil belajar siswa pada materi sistem pencernaan manusia di kelas VIII SMP Negeri 4 Melonguane.
\end{abstract}

Kata kunci: contextual teaching and learning, hasil belajar

\begin{abstract}
This research was conducted to determine the effect of using the Contextual Teaching and Learning (CTL) learning model assisted by teaching aids on student learning outcomes in the human digestive system material. This research was conducted at SMP Negeri 4 Melonguane in the odd semester of the 2019-2020 school year. This research is using experimental method. The population in this study were all students of class VIII which consisted of 2 classes. Sampling was carried out in 2 available classes, with a total of 19 students each. Class VIII-A as the experimental class and class VIII-B as the control class. Student learning outcomes data obtained from the pretest and posttest. The results showed that the two-mean difference test (t-test) at the 0.05 level obtained $t_{\text {count }}=3.55$ and $t_{\text {table }}=2.10$, thus indicating that the average learning outcomes of students using the CTL learning model were higher than the average learning outcomes of students using conventional models. So, it can be concluded that there is an effect of the CTL learning model assisted by teaching aids on student learning outcomes on the material of the human digestive system in class VIII SMP Negeri 4 Melonguane.

Keywords: contextual teaching and learning, learning outcomes
\end{abstract}

Diterima 20 November 2020 | Disetujui 23 Desember 2020 | Diterbitkan 31 Desember 2020

\section{PENDAHULUAN}

Pendidikan merupakan segala situasi hidup yang mempengaruhi pertumbuhan individu sebagai pengalaman belajar yang berlangsung dalam segala lingkungan dan sepanjang 
hidup. Dalam arti sempit, pendidikan adalah pengajaran yang diselenggarakan umumnya di sekolah sebagai lembaga pendidikan formal. Pendidikan bertujuan membantu seseorang untuk mempelajari berbagai hal yang belum diketahuinya untuk menumbuhkembangkan potensipotensi yang dimiliki. Salah satu mata pelajaran yang dipelajari dalam pendidikan formal adalah pelajaran IPA (Putri, Candiasa \& Marhaeni, 2014).

Pendidikan IPA adalah bagian dari materi pendidikan formal yang mampu memberikan kontribusi kepada sumber daya manusia yang berkualitas. Penguasaan IPA melalui pembelajaran secara teoritis sangat ditentukan oleh kemampuan dan kreatifitas siswa dalam menguasai keterampilan proses sains. Siswa yang mempunyai keterampilan proses bagus maka prestasi akademiknya juga bagus (Sulthon, 2016). Pada prinsipnya, IPA diajarkan untuk membekali siswa agar mempunyai pengetahuan dan keterampilan yang dapat membantu siswa untuk memahami gejala alam secara mendalam (Hendro, 1991).

Berdasarkan observasi awal melalui wawancara kepada guru IPA di SMP Negeri 4 Melonguane, ditemukan bahwa keadaan sekolah cukup baik dengan fasilitas yang cukup lengkap. Akan tetapi, dari semua fasilitas yang baik ditemukan adanya kendala yang dapat dilihat dari presentase hasil ujian siswa kelas VIII tahun ajaran 2018/2019 hanya 35\%-65\% saja. Sedangkan, keberhasilan belajar yang diharapkan $85 \%$ dari seluruh siswa yang mencapai kriteria ketuntasan maksimal (KKM). Dimana nilai dari kriteria ketuntasan minimal (KKM) yakni 67. Ternyata setelah diselediki penyebab proses pembelajaran yang kurang optimal, diantaranya penggunaan model pemembelajaran IPA yang sudah dipakai tapi belum efektif karna hanya sedikit dipakai dipelajaran serta kurangnya penggunaan media pembelajaran khususnya materi sistem pencernaan.

Pembelajaran IPA tidak bisa dengan cara menghafal atau pasif mendengarkan guru menjelaskan konsep namun siswa sendiri yang harus melakukan pembelajaran melalui percobaan, pengamatan maupun bereksperimen secara aktif yang akhirnya akan terbentuk kreativitas dan kesadaran untuk menjaga dan memperbaiki gejalagejala alam yang terjadi untuk selanjutnya membentuk sikap ilmiah yang pada gilirannya akan aktif untuk menjaga kestabilan alam ini secara baik dan lestari.

Guru diharapkan mampu mengajarkan pembelajaran IPA dengan baik dan benar agar peserta didik mudah memahami isi pembelajaran IPA. Pada saat mengajar guru haruslah kreatif dan bervariatif dalam hal memilih dan memilah metode, model, pendekatan, dan pengelolaan kelas. Hal itu akan mempermudah peserta didik untuk mencerna materi yang disampaikan oleh guru. Salah satu cara untuk melakukan sesuatu yang berbeda di dalam mengajar adalah dengan menggunakan model pembelajaran yang dipadukan dengan alat peraga (Handini, Diah \& Regina, 2016). Oleh karena itu, peneliti merasa perlu adanya bantuan media pembelajaran dalam hal ini yaitu alat peraga sederhana untuk mendukung model pembelajaran CTL.

Terdapat tujuh komponen utama dalam CTL yaitu kontruktivisme, bertanya, inquiry, masyarakat belajar, pemodelan, refleksi dan penilaian autentik (Elaine, 2007). Komponenkomponen tersebut mendorong keterlibatan siswa secara penuh dalam menemukan pengetahuan mereka, sehingga siswa akan lebih termotivasi dalam mengikuti kegiatan pembelajaran. Proses belajar akan berlangsung secara optimal jika proses pembelajaran diawali dengan tahapan enaktif yaitu tahapan pembelajaran suatu pengetahuan di mana pengetahuan itu dipelajari secara aktif, dengan menggunakan benda-benda kongkret atau menggunakan situasi yang nyata (Indrawati, 2009).

Alat peraga adalah alat bantu dalam proses pengajaran yang berfungsi untuk memperjelas guru saat mengajar dan siswa saat belajar. Jadi, alat peraga dalam mengajar memegang peranan 
penting sebagai alat bantu untuk menciptakan proses pembelajaran yang efektif. Alat peraga juga dapat mengoptimalkan waktu yang cenderung sedikit, sedangkan materi yang harus disampaikan lumayan banyak, karena didalam alat peraga bisa menyampaikan beberapa konsep yang dikemas menjadi satu (Sudjana, 2014). Alat peraga yang digunakan dalam penelitian ini yaitu alat peraga sistem pencernaan yang dibuat sendiri oleh peneliti.

Berdasarkan hal ini, peneliti menerapkan model pembelajaran CTL berbantuan alat peraga pada pembelajaran IPA sebagai upaya dalam meningkatkan hasil belajar siswa. Penelitian ini bertujuan untuk mengetahui pengaruh penggunaan model pembelajaran Contextual Teaching and Learning berbantuan alat peraga terhadap hasil belajar siswa pada materi sistem pencernaan manusia.

\section{METODE PENELITIAN}

Penelitian dilaksanakan di kelas VIII SMP Negeri 4 Melonguane, dengan waktu pelaksanaan pada semester ganjil tahun ajaran 2019/2020. Metode penelitian ini mengunakan metode eksperimen semu, dengan analisis uji-t yang menganalisis pengaruh variabel $\mathrm{X}$ terhadap Y (Sugiono, 2013), berdasarkan perbedaan hasil belajar antara kelompok yang diberikan perlakuan model pembelajaran CTL berbantuan alat peraga dan tanpa mengunakan model pembelajaran CTL berbantuan alat peraga.

Populasi dalam penelitian ini adalah seluruh siswa kelas VIII yang terdiri atas 2 kelas. Kelas VIII-A dengan jumlah 19 orang dan kelas VIII-B dengan jumlah 19 orang. Pengambilan sampel dilakukan pada 2 kelas yang tersedia yaitu kelas VIII-A dan kelas VIII-B sebagai kelas eksperimen dan kelas kontrol.

Instrumen yang digunakan dalam penelitian ini berupa tes tertulis bentuk tes pilihan ganda dan uraian. Sedangkan teknik pengumpulan data pada kelas eksperimen dan kelas kontrol keduanya diberikan pretest (tes awal) dan posttest (tes akhir). Teknik yang digunakan untuk analisis data pada penelitian dibagi menjadi 2 tahap, yaitu tahap awal dengan melakukan uji normalitas data dengan uji Lilliefors dan uji homogenitas data dengan uji $\mathrm{F}$ serta tahap akhir dengan menggunakan uji-t untuk pengujian hipotesis.

\section{HASIL DAN PEMBAHASAN Hasil Penelitian}

Penelitian ini diperoleh data dari 19 orang siswa di kelas VIII-A yang menggunakan model pembelajaran CTL berbantuan alat peraga dan 19 orang siswa kelas VIII-B tanpa menggunakan model pembelajaran CTL. Data proses dan hasil belajar siswa diperoleh berdasarkan perlakuan yang diberikan oleh kedua kelas yang masing-masing terdiri atas kelas eksperimen dan kelas kontrol yang pengambilan datanya diambil menggunakan pretest dan posttest berupa soal uraian.

Data hasil belajar siswa tersebut di analisis menggunakan uji-t. Rata-rata hasil belajar siswa pada materi sistem pencernaan dapat dilihat dari hasil analisis deskriptif data pretest dan posttest kelas VIII-A dapat dilihat pada Tabel 1.

Tabel 1. Ringkasan data selisih skor pretest dan posttest kelas eksperimen menggunakan model pembelajaran CTL

\begin{tabular}{llll}
\hline Statistik & Pretest & Posttest & Selisih \\
\hline $\begin{array}{l}\text { Jumlah } \\
\begin{array}{l}\text { Skor } \\
\text { minimum }\end{array}\end{array}$ & 441 & 1444 & 1001 \\
$\begin{array}{l}\text { Skor } \\
\text { maksimum }\end{array}$ & 40 & 65 & 35 \\
$\begin{array}{l}\text { Rata-rata } \\
\text { Standar }\end{array}$ & 23,2 & 88 & 53 \\
deviasi & 8,20 & 6,80 & 52,6 \\
Varians & 67,3 & 46,3 & 78,85 \\
\hline
\end{tabular}

Pada Tabel 1, terlihat bahwa ratarata hasil pretest pada kelas eksperimen 23,2 dengan skor minimum 15 dan terdapat peningkatan pada rata-rata hasil posttest kelas eksperimen menjadi 76 dengan diperoleh skor minimum 65 .

Adapun rata-rata hasil belajar siswa pada materi sistem pencernaan dapat dilihat dari hasil analisis deskriptif data 
pretest dan postest kelas VIII-B pada Tabel 2.

Tabel 2. Ringkasan data selisih skor pretest dan posttest kelas kontrol menggunakan model pembelajaran konvensional

\begin{tabular}{llll}
\hline Statistik & Pretest & Posttest & Selisih \\
\hline $\begin{array}{l}\text { Jumlah } \\
\begin{array}{l}\text { Skor } \\
\text { minimum }\end{array}\end{array}$ & 411 & 1366 & 955 \\
$\begin{array}{l}\text { Skor } \\
\text { maksimum }\end{array}$ & 40 & 62 & 32 \\
$\begin{array}{l}\text { Rata-rata } \\
\begin{array}{l}\text { Standar } \\
\text { deviasi }\end{array}\end{array}$ & 21,6 & 85 & 66 \\
Varians & 8,34 & 6,39 & 50,2 \\
\hline
\end{tabular}

Pada Tabel 2 menunjukkan bahwa rata-rata hasil pretest pada kelas kontrol 21,6 dengan skor minimum 11 dan kemudian terdapat peningkatan pada rata-rata hasil posttest kelas kontrol menjadi 71,8 dengan diperoleh skor minimum 40.

Uji normalitas dan homogenitas data diperoleh bahwa data berdistribusi normal dan varians dari kedua populasi asal sampel penelitian adalah homogen. Oleh karena itu, statistic uji-t dapat dilanjutkan.

Pada taraf nyata $(\alpha)=0,05 \mathrm{di}$ peroleh $t_{\text {hitung }}=3,55$ dan $t_{\text {tabel }}=2,10$. Jadi $t_{\text {hitung }}=3,55>t_{\text {tabel }}=2,10$ yang artinya statistik uji tersebut jatuh di wilayah kritis. Hal ini menunjukan bahwa tidak cukup bukti untuk menerima $\mathrm{H}_{0}$. Oleh karena itu, disimpulkan bahwa tolak $\mathrm{H}_{0}$ dan terima $\mathrm{H}_{1}$ yaitu $\mu_{1}>\mu_{2}$. Hal ini berarti bahwa rata-rata hasil belajar siswa yang yang menggunakan model pembelajaran CTL berbantuan alat peraga lebih tinggi dari pada rata-rata hasil belajar siswa yang menggunakan model pembelajaran konvensional.

\section{Pembahasan}

Hasil penelitian di kelas eksperimen pada materi sistem pencernaan, menunjukkan adanya pengaruh positif yang nyata akan penggunaan perlakuan tersebut terhadap peningkatan hasil belajar siswa. Hal ini ditunjukkan dengan rata-rata hasil tes yang diberikan kepada kedua kelas dimana skor pretest kelas eksperimen adalah 23,2 yang kemudian mengalami peningkatan pada skor posttest 76 dari skor ideal 100, dan untuk kelas kontrol diperoleh rata-rata nilai pretest adalah 21,6 sedangkan skor posttest adalah 71,8 dari skor ideal 100, dan kemudian rata-rata selisih posttespretest untuk kelas eksperimen adalah 52,6 sedangkan untuk kelas kontrol di peroleh 50,2 dari 19 siswa untuk kelas eksperimen dan 19 siswa untuk kelas kontrol. Hal ini memperlihatkan selisih peningkatan skor hasil pretest dan posttest untuk kelas eksperimen lebih besar dari pada selisih peningkatan skor hasil pretest dan posttest untuk kelas kontrol. Pada pengujian hipotesis dengan menggunakan uji perbedaan dua ratarata, di peroleh hasil dimana thitung $>t_{\text {tabel, }}$, sehingga $\mathrm{H}_{0}$ ditolak dan $\mathrm{H}_{1}$ diterima.

Berdasarkan hasil analisis data dapat dilihat bahwa rata-rata hasil belajar kelas eksperimen lebih tinggi dibandingkan dengan kelas kontrol, sehingga dapat ditarik sebuah kesimpulan bahwa rata-rata hasil belajar siswa yang mengunakan model pembelajaran CTL berbantuan alat peraga lebih tinggi daripada rata-rata hasil belajar siswa yang menggunakan model pembelajaran konvensional (ceramah). Selain itu, pembelajaran pada materi sistem pencernaan manusia dengan menggunakan model pembelajaran CTL berbantuan alat peraga dapat meningkatkan keaktifan belajar siswa selama pembelajaran berlangsung.

Belajar yaitu aktifitas mental atau psikis yang berlangsung dalam interaksi aktif dengan lingkungan yang maknanya adalah pengalaman (Elaine, 2007). Hal ini menunjukan bahwa, belajar memerlukan proses yang baik dan aktif agar siswa memiliki pengalaman dan mengambil ulang pengalaman yang pernah mereka peroleh. Guru juga memberikan kesempatan kepada siswa melalui kegiatan diskusi, sehingga mendorong adanya interaksi antar teman maka pembelajaran memungkinkan siswa bersosialisasi dengan menghargai perbedaan pendapat dan berlatih untuk 
bekerja sama. Semakin sering dilaksanakan kegiatan diskusi dapat meningkatkan interaksi serta kerja sama.

Hal ini menunjukkan adanya peningkatan partisipasi siswa. Hasil belajar ini merefleksikan keleluasaan, kedalaman, dan kompleksitas (secara bergradasi) dan digambarkan secara jelas serta dapat diukur dengan teknik-teknik penilaian tertentu. menyatakan bahwa proses penilaian terhadap hasil belajar dapat memberikan informasi kepada guru tentang kemajuan siswa dalam upaya mencapai tujuan-tujuan belajarnya melalui kegiatan belajar. Oleh karena itu, penilaian hasil belajar mempunyai peranan yang penting dalam proses belajar. Pengalaman yang diperoleh oleh siswa melalui pembelajaran yang mampu mengerahkan kemampuannya untuk mencari ide-ide dan mengagali pengalamannya serta mencari hal yang ada disekitarnya sebagai objek belajar, hal ini akan memberikan keleluasaan, kedalaman dan kompleksitas dalam menghimpun materi pembelajaran (Sudjana \& Rivai, 2009).

Pembelajaran ini memiliki banyak faktor yang harus dipenuhi agar dapat berjalan dengan baik. Hal ini disebabkan oleh keadaan siswa, guru dan lingkungan sekolah yang berbeda sehingga perlu adanya penyesuaian antara materi dan model pembelajaran terhadap siswa. Dimana siswa memiliki kelebihan dan kekurangan masing-masing yang berbeda yang mengharuskan seorang guru mampu mengemas pembelajaran dengan baik. Siswa memiliki karakter yang berbedabeda sehingga guru harus mampu mengerti kebutuhan masing-masing siswa yang lebih mengutamakan kepentingan siswa. Ketercapaian nilai hasil belajar yang baik merupakan salah satu tolak ukur keberhasilan dalam pembelajaran.

\section{KESIMPULAN}

Berdasarkan hasil penelitian yang telah dilakukan, dapat disimpulkan bahwa terdapat pengaruh model pembelajaran Contextual Teaching and Learning berbantuan alat peraga terhadap hasil belajar siswa pada materi sistem pencernaan manusia di kelas VIII SMP Negeri 4 Melonguane.

\section{DAFTAR PUSTAKA}

Elaine. (2007). Contextual Teaching and Learning Menjadikan Kegiatan Belajar-Mengajar Lebih Mengasyikkan dan Bermakna. Bandung: Mizan Learning Center.

Handini, D., Diah G., \& Regina L. P. (2016). Penerapan Model Contextual Teaching and Learning Meningkatkan Hasil Belajar Siswa Kelas IV Pada Materi Gaya. Jurnal Pena Ilmiah, 1(1), 451-560.

Hendro. (1991). Pendidikan IPA 2. Jakarta: Depdikbub.

Indrawati. (2009). Model Pembelajaran Terpadu di Sekolah Dasar. Bandung: P4TKIPA.

Putri, S., Candiasa, I. M., Kom, M. I., \& Marhaeni, A. N. (2014). Pengaruh Implementasi Metode Inkuiri Terbimbing Berbasis Asesmen Kinerja Terhadap Hasil Belajar IPA Ditinjau Dari Sikap Ilmiah Siswa Kelas VIII SMP Negeri 1 Tegallalang. Jurnal Penelitian dan Evaluasi Pendidikan Indonesia, 4(1).

Sudjana, N. (2014). Dasar-Dasar Proses Belajar Mengajar. Bandung: Sinar Baru Algensindo.

Sudjana, N. \& Rivai, A. (2009). Media Pembelajaran. Bandung: Sinar Baru Algesindo.

Sugiyono. (2013). Statistika Untuk Penelitian. Bandung: Alfabeta

Sulthon, S. (2016). Pembelajaran IPA Yang Efektif Dan Menyenangkan Bagi Siswa MI. Elementary, 4(1). 